\title{
Outcome of Laparoscopic Ovarian Drilling (LOD) for Women with Polycystic Ovary Syndrome.
}

\author{
Rifat Syed ${ }^{1}$, Jamal Zaidi ${ }^{2}$, and Nabeha Dhar ${ }^{3}$ \\ ${ }^{1}$ Dartford and Gravesham NHS Trust \\ ${ }^{2}$ Conquest Hospital \\ ${ }^{3}$ Affiliation not available
}

June 2, 2020

\begin{abstract}
Objective: To evaluate the effectivity of laparoscopic ovarian drilling procedures at the East Sussex Healthcare Trust, UK, over the past decade on sub-fertile women with polycystic ovary syndrome, regardless of clomiphene resistance. Design: Retrospective case note review of LOD procedures Methods: *Study 1: Evaluating a systematic literature review investigating ovulation and pregnancy rates following LOD. *Study 2: An audit of 58 women with LOD treated for ovulation induction at the ESHT fertility clinic between 2005-2014. Main outcome measures: Ovulation, pregnancy, live birth, miscarriage rates; tubal patency; associated pathologies; previous treatments compared with Cochrane Review 2012. Results: *Study 1: From the literature review, $71 \%$ achieved ovulation, whereas the pregnancy, live birth and miscarriage rates were $25-51 \%, 24-44 \%$ and $4-9 \%$ respectively. ${ }^{*}$ Study 2 : Of the 58 patients studied, ovulation rate was $69 \%$, pregnancy rate was $39.4 \%$ and live birth rate was $30.3 \%$. The miscarriage rate was $15.4 \%$. Pregnancy outcome after LOD, irrespective of further treatment, showed 34 pregnancies. Including 17 spontaneous pregnancies and 17 pregnancies after further treatment. Of the 34 pregnancies, $85.3 \%$ were live birth, $11.7 \%$ miscarriages and 1 ectopic pregnancy. Conclusion: No significant difference in ovulation rates post-LOD in ESHT, which is comparable to published studies. The low pregnancy and live birth rates indicate that additional factors affect the success of LOD. Co-existing pathology is associated with lower pregnancy rate post-LOD. Novel theories are postulated to explain underlying pathologies, thus PCOS treatment may change and open a fascinating area of research. Keywords: polycystic ovary syndrome, laparoscopic ovarian drilling, clomiphene citrate
\end{abstract}

\section{Hosted file}

manuscript.docx available at https://authorea.com/users/328805/articles/456122-outcome-oflaparoscopic-ovarian-drilling-lod-for-women-with-polycystic-ovary-syndrome 




Figure 1 shows the age of the patient when having $L O D$.

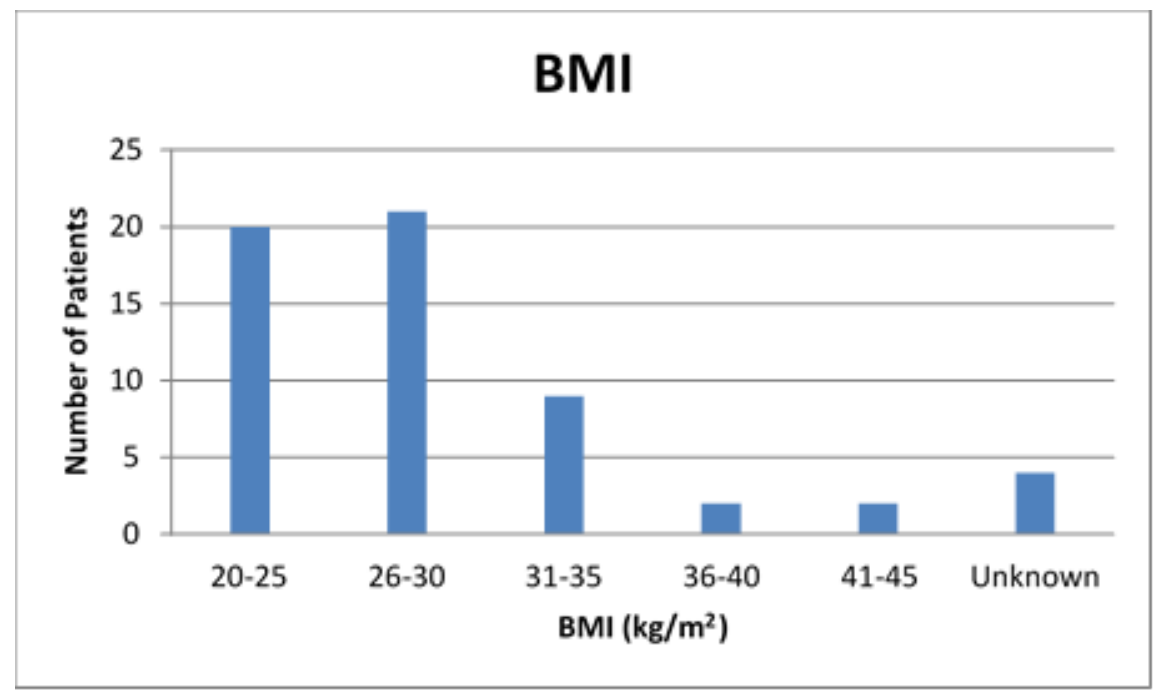

Figure 2 shows the BMI of 58 patients when having LOD. 




Figure 3 shows the duration of subfertility before $L O D$.

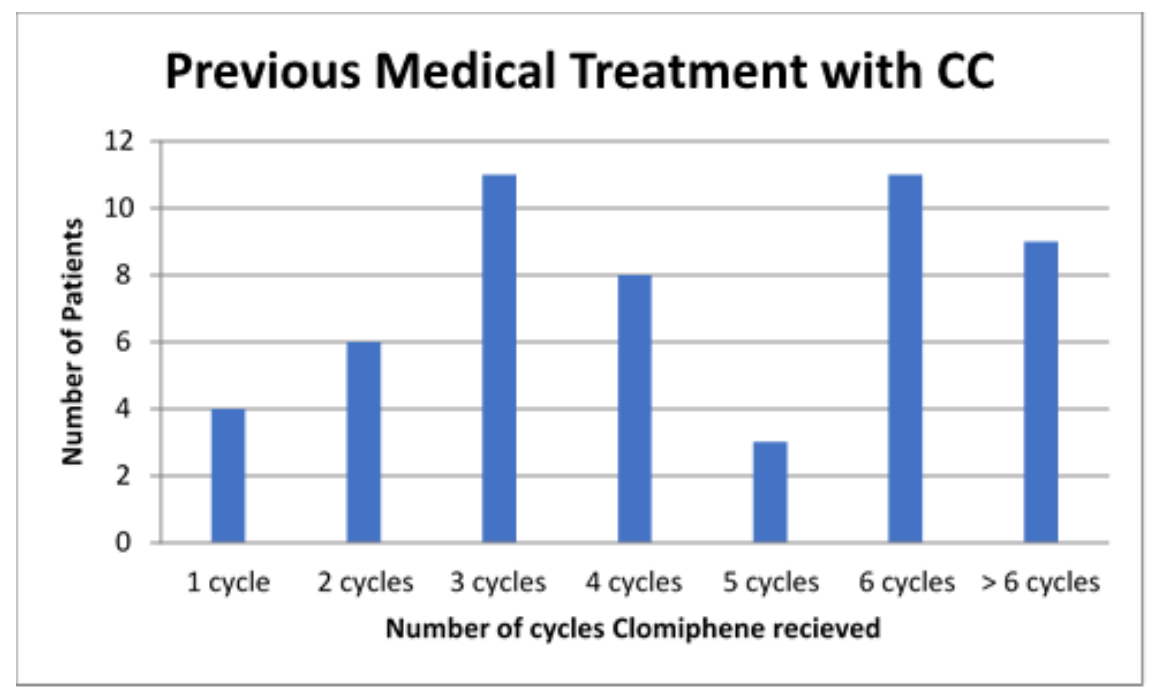

Figure 4 shows the number of cycles of CC before 


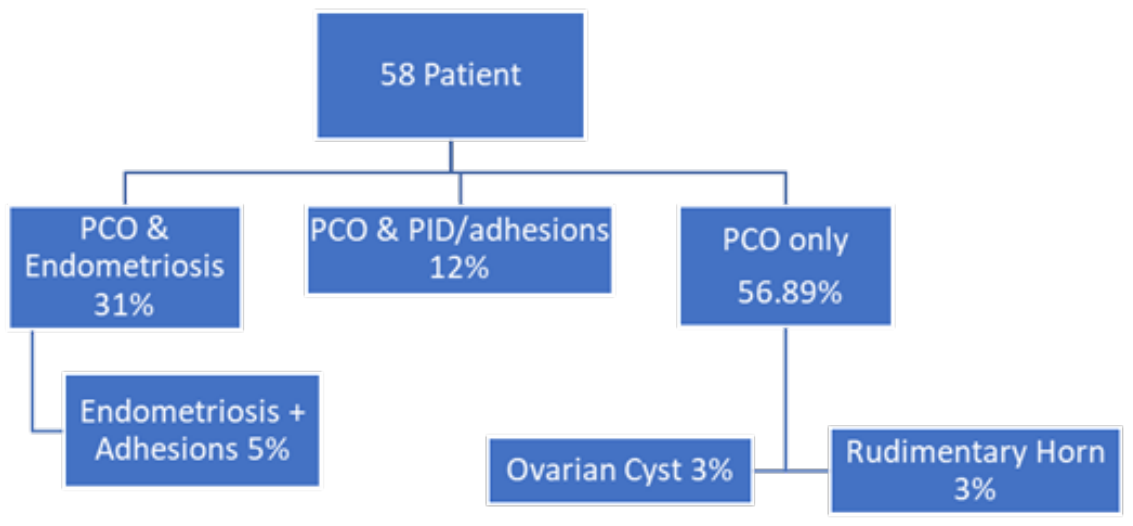

Figure 5 shows operative findings in $L O D$



Figure 6 shows tubal patency done at LOD.



Figure 7 shows the different treatments underwent by the 41 patients who did not conceive after LOD. 


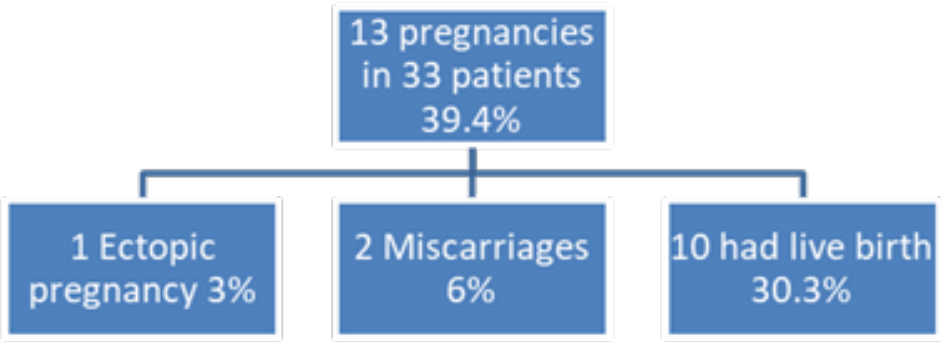

Figure 8 shows the outcome of spontaneous pregnancies in pure PCOS patients.



Figure 9 shows the rate of spontaneous pregnancies in correlation to the associated pathologies. 